\title{
SISTEMA TRIBUTÁRIO NACIONAL E POLÍTICA NACIONAL DO MEIO AMBIENTE: A Extrafiscalidade Pró-Ambiente
}

\author{
NATIONAL TAX SYSTEM AND NATIONAL ENVIRONMENTAL POLICY
}

MARCOS AURÉLIO DOS SANTOS BORGES ${ }^{1}$

\begin{abstract}
RESUMO
O presente texto visa tecer considerações sobre o liame existente entre o Sistema Tributário Nacional e a Política Nacional do Meio Ambiente, através da abordagem acerca dos tributos em espécie e o caráter extrafiscal, propício para contribuir para as políticas ambientais, bem como o impacto das repartições constitucionais das receitas tributárias nas ações preventivas de proteção ambiental. Ademais, aborda questões internacionais e a relação com o meio ambiente nacional, além de evidenciar algumas experiências positivas existentes na região amazônica, no que se refere a empreendimentos industriais e as receitas tributárias geradas, levando em consideração o meio ambiente.
\end{abstract}

Palavras-chave: Sistema Tributário Nacional. Política Nacional do Meio Ambiente. Extrafiscalidade

\begin{abstract}
This paper seeks comment on the bond between the National Tax System and the National Environment Policy, through the approach on taxes in kind and their character, suitable for contributing environmental policies, as well as the impact of constitutional breakdowns of revenues tax on preventive environmental protection. In addition to addressing international issues and the relationship with the environment nationwide, some positive experiences existing in the Amazon region, with regard to industrial enterprises and tax revenue generated, taking into consideration the environment.
\end{abstract}

Keywords: National Tax System. National Environment Policy. Extrafiscality.

\section{CONSIDERAÇÕES INICIAIS}

A atual ordem constitucional inaugurada em 1988 trouxe novos paradigmas acerca de quais direitos seriam tutelados pela Constituição Federal, como forma de assegurar a estabilidade de um Estado Democrático e de Direito.

Princípios, como os da dignidade da pessoa humana, livre concorrência, limitações ao poder de tributar e o do meio ambiente ecologicamente equilibrado, presentes, respectivamente, nos art. $1^{\circ}$, III; 170, IV; 146,II e 225, todos da Constituição Federal, são

\footnotetext{
1 Advogado atuante no Pará e no Rio de Janeiro nas áreas de Direito Tributário, Empresarial e Internacional. Graduado em Direito pela Universidade Federal do Pará. Especializado em Direito Empresarial e Tributário Fundação Getúlio Vargas/RJ e, em Direito Internacional por título conferido pelo Comitê Jurídico Interamericano da Organização dos Estados Americanos. Parecerista-Avaliador ad hoc da Universidade Federal de Uberlândia. Mestrando em Direito Internacional - Universidade Gama Filho/RJ.
} 
marcos que devem ser preservados em nossa ordem jurídica, já que foram eleitos pelo constituinte originário, como referências para o novo ordenamento jurídico.

Estes princípios se relacionam, na medida em que regem as relações jurídicas entre cidadãos em grau de igualdade, mas, principalmente, se direciona ao Estado, no tocante à sua atuação para com seus nacionais brasileiros.

Neste contexto existe a convivência necessária entre o sistema tributário nacional e a política nacional do meio ambiente.

Fernando Magalhães Modé, no título da sua obra expõe, o termo "Tributação Ambiental", Silvério Ramos, Stefania Eugenia Barichello e Luiz Ernani Bonesso de Araújo,

O termo é equivocado, por dois motivos. O primeiro se encontra no fato de que tributação enseja um fazer do Estado, mais precisamente, na criação de tributos incidentes sobre o meio ambiente. Sendo assim, do ponto de vista técnico, isto é impossível, na medida em que considera o meio ambiente um bem privado, sujeito à incidência de tributos, contrariando o explicitado no art. 225 da $\mathrm{CF}$, que prevê que o meio ambiente é bem de uso comum do povo. Já o segundo está pautado na realidade. O que ocorre são incentivos fiscais àqueles que regem suas atividades produtivas pautadas na preservação ambiental, ou uma majoração dos tributos já existentes com o intuito de reprimir práticas produtivas deletérias ao meio ambiente, como forma de efetivar o equilíbrio entre os agentes econômicos concorrentes.

Outro ponto de extrema relevância mencionado por Modé é a de que tal "tributação" não tem caráter sancionatório. Em suas palavras, ele afirma: "a tributação ambiental diferencia-se do caráter sancionatório por não se aplicar a atividades ilícitas. A tributação ambiental aplica-se tão somente à atividades lícitas, assim consideradas pelo legislador porque necessárias, em que pese o impacto do meio ambiente."3

Ora, nenhuma atividade tributária em qualquer das esferas, sejam elas federal, estadual ou municipal, tem natureza sancionatória. Pela própria redação do art. $3^{\circ}$ do Código Tributário Nacional, onde há a clara menção que tributo não decorre de sanção de ato ilícito, depreende-se tal entendimento.

Diante destas premissas, este trabalho pretende abordar a relação existente entre o sistema tributário nacional e a política nacional do meio ambiente, os aspectos positivos e

\footnotetext{
${ }^{2}$ MODÉ, Fernando Magalhães. Tributação Ambiental. Curitiba: Juruá, 2003, p. 123. In BARICHELO, Stefania Eugenia e ARAÚJO, Luiz Ernani Bonesso. Fórum de Direito Urbano e Ambiental - FDUA. ano 1, n.1, jan/fev. 2002. Belo Horizonte: Fórum, 2002, p.69.

${ }^{3}$ MODÉ, Fernando Magalhães, op.cit.,p.123.
} 
negativos, bem como apontar sugestões para aprimoramento daquela, em prol do benefício do Estado brasileiro.

Desse modo, os recursos arrecadados com a tributação são parcialmente revertidos em benefício do meio ambiente e constituem ponto fulcral para a construção de uma sociedade livre, justa e solidária, objetivo fundamental a ser perseguido e alcançado pelo Estado Brasileiro, conforme prevê o art. $2^{\circ}$, I, da CF.

\section{ELO CONSTITUCIONAL ENTRE ORDEM ECONÔMICA, SISTEMA TRIBUTÁRIO NACIONAL E MEIO AMBIENTE}

A Teoria Tridimensional do Direito proposta por Miguel Reale ${ }^{4}$ indica que a atividade jurídica ou o fenômeno jurídico tem como pressupostos o fato social, valor e a norma. Consiste no raciocínio lógico efetuado pelo agente normatizador em que diante de um fato social relevante, estabelece certo aspecto axiológico ou carga valorativa, a fim de que resulte numa norma jurídica.

Se levarmos este entendimento para o ângulo constitucional e, tendo em vista que o agente normatizador primário de um estado moderno é povo, que detém o poder constituinte originário, temos que este irá analisar um fato social, estabelecer um valor e criará uma norma.

Tal norma ao ser criada pelo poder constituinte originário tem caráter constitucional e, portanto, gozará de grau elevado de aplicabilidade dentro do ordenamento jurídico brasileiro.

José Afonso da Silva, em sua obra "Aplicabilidade das normas constitucionais" estabelece uma divisão tripartite da aplicabilidade destas normas. $\mathrm{O}$ autor diz que as normas constitucionais tem eficácia plena, contida ou limitada.

Para ele as normas constitucionais de eficácia plena são:

as que receberam do constituinte normatividade suficiente à sua incidência imediata. Situam-se predominantemente entre os elementos orgânicos da constituição. Não necessitam de providência normativa ulterior para a sua aplicação. Criam situações subjetivas de vantagem ou desde logo exigíveis ${ }^{5}$

Já as normas constitucionais de eficácia contida são aquelas que:

o legislador constituinte regulou suficientemente os interesses relativos a determinada matéria, mas deixou margem à atuação restritiva por parte da competência discricionária do Poder Público, nos termos que a lei estabelecer ou nos termos dos conceitos gerais nela enunciados. ${ }^{6}$

\footnotetext{
${ }^{4}$ REALE, Miguel. Teoria Tridimensional do Direito. $5^{\text {a }}$ ed. São Paulo: Saraiva, 1994.

${ }^{5}$ SILVA, José Afonso. Aplicabilidade das normas constitucionais. $3^{\text {a }}$ ed. rev. e ampl., São Paulo: Malheiros, 1998, p. 262.

${ }^{6} I d, \mathrm{p} .116$.
} 
Por sua vez as normas constitucionais de eficácia limitada são:

as que não receberam do constituinte normatividade suficiente para a sua aplicação, o qual deixou ao legislador ordinário a tarefa de completar a regulamentação das matérias nela traçadas em princípio ou esquema

Desta maneira, a Constituição Federal promulgada em 5 de outubro de 1988 merece aplausos e elogios, ao estabelecer em seu texto um dispositivo de eficácia limitada, que tem a capacidade de sintetizar e unir toda a relação existente entre a atividade empresarial, o sistema tributário brasileiro e aspectos legais protetivos ao meio ambiente. Este dispositivo é de uma superioridade intelectual soberba, pois concatena princípios e valores presentes na sociedade brasileira.

Tal dispositivo encontra-se no art. 170, VI, da CF, que afirma:

A ordem econômica, fundada na valorização do trabalho humano e na livre iniciativa, tem por fim assegurar a todos a existência digna, conforme os ditames da justiça social, observados os seguintes princípios:

VI - defesa do meio ambiente, inclusive mediante tratamento diferenciado conforme o impacto ambiental dos produtos e serviços e de seus processos de elaboração e prestação.

Da leitura deste dispositivo vislumbra-se perfeitamente o elo existente entre a ordem econômica, o sistema tributário nacional e o meio ambiente, na medida em que a atividade econômica deve ser realizada de modo a não ocasionar ou minimizar os impactos ambientais, bem como ser observada de perto pelo Estado através do poder de polícia ou de aspectos tributários.

Em outras palavras, toda a demonstração de riqueza externalizada pelo contribuinte será fonte de arrecadação de recursos, através da tributação, com o intuito de atingir os interesses públicos, dentre eles o meio ambiente saudável, através de medidas públicas a serem comentadas posteriormente.

\section{TRIBUTOS E SUAS DIMENSÕES FINALÍSTICAS}

Em uma análise sintética da atividade estatal tributária, percebe-se apenas uma dessas dimensões, a chamada finalidade fiscal, deixando de fora as finalidades extrafiscal e a parafiscal.

Esclarecendo tais termos, temos que o tributo tem finalidade fiscal quando tem como objetivo principal obter recursos destinados aos cofres públicos. Nos dizeres de Ricardo 
Alexandre, temos que "o tributo possui finalidade fiscal quando visa precipuamente a arrecadar, carrear recursos para os cofres públicos.",7

O tributo tem finalidade extrafiscal quando atua como interventor em situações econômicas, estimulando ou inibindo determinada atividade econômica. Ricardo Alexandre expõe: “o tributo possui finalidade extrafiscal quando objetiva fundamentalmente intervir numa situação social ou econômica." ${ }^{8}$

Por fim, a finalidade parafiscal do tributo encontra-se no fato de que a lei estipula a outro sujeito ativo, diferente do ente instituidor, que disponha dos recursos obtidos para o alcance dos objetivos almejados. O autor diz: "o tributo possui finalidade parafiscal quando a lei tributária nomeia sujeito ativo diverso da pessoa que a expediu, atribuindo-lhe a disponibilidade dos recursos para o implemento dos seus objetivos."9

É no contexto da extrafiscalidade que os tributos se relacionam com a política nacional do meio ambiente, proporcionando uma proteção maior ao meio ambiente, criando uma consciência ambiental positiva no setor produtivo, bem como promove uma tributação equitativa entre os contribuintes. A extrafiscalidade, portanto, decorre da utilização da norma tributária com o escopo de direcionar, de forma positiva, o comportamento do contribuinte.

O Estado, ao conceder benefícios fiscais aos contribuintes que investem em melhorias na sua cadeia produtiva, a ponto de minimizar ou erradicar os impactos ambientais da atividade econômica, assim como impor o pagamento de tributos mais onerosos em setores que o poder de polícia estatal tem que manter atuação constante, devido a sua grande capacidade de poluição de diversos tipos de setores produtivos, e também elevar alíquotas tributárias a fim de desestimular práticas ambientais deletérias, representam a dimensão extrafiscal da tributação voltadas à proteção do meio ambiente saudável.

O mecanismo da extrafiscalidade consiste em uma ferramenta essencial nas mãos dos entes tributantes, pois conseguem intervir no setor produtivo, a fim de que as atividades econômicas desempenhadas por estes contribuintes, estejam adequadas aos ditames legais, assim como direcionam as atividades empresariais para uma forma de atuação condizente com os deveres de proteção ao meio ambiente, assegurando um bem estar generalizado, usufruído por estes e por todos os outros integrantes da sociedade brasileira, que possuem o direito de viver em um ambiente saudável.

\footnotetext{
${ }^{7}$ ALEXANDRE, Ricardo. Direito tributário esquematizado. $2^{\mathrm{a}}$ ed. atual. ampl. São Paulo: Método, 2008, p.86

${ }^{8}$ Loc.cit.

${ }^{9}$ Loc.cit.
} 


\title{
4. ESPÉCIES TRIBUTÁRIAS E SUA VOCAÇÃO EXTRAFISCAL
}

A doutrina tributária majoritária nacional adotou a divisão pentapartite de espécies tributárias, corroborada pelo Supremo Tribunal Federal, das quais temos como espécies tributárias os impostos, as taxas, as contribuições de melhorias, os empréstimos compulsórios e as contribuições especiais, apesar do Código Tributário elencar apenas três daquelas espécies em seu art. $5^{\circ}$.

Cada uma destas espécies tributárias tem, principalmente, a finalidade fiscal, a qual consiste em carrear recursos para os cofres públicos. Todavia, algumas delas possuem uma vocação para a extrafiscalidade, que se adequa perfeitamente aos objetivos protetivos do meio ambiente.

\subsection{Impostos}

Consiste em uma espécie tributária presente no art. 145, I da CF e da sua previsão no art. 16 do Código Tributário Nacional - CTN, tem-se que: "Imposto é tributo cuja obrigação tem por fato gerador uma situação independente de qualquer atividade estatal específica, relativa ao contribuinte."

Desse modo, o imposto é tributo geral, cuja receita não possui nenhuma vinculação à atividade contraprestacional estatal, possui característica eminentemente fiscal, porém, também possui um enorme potencial extrafiscal, principalmente os chamados impostos aduaneiros que controlam a importação e exportação de mercadorias e serviços.

Luis Augusto Stumpf Luz afirma que:

\begin{abstract}
os impostos podem ser amplamente utilizados como instrumentos de tributação ambiental, através de um sistema de isenções e restituições, conforme a natureza dos produtos ou mercadorias estimulando as atividades não poluidoras e desestimulando aquelas poluidoras. ${ }^{10}$
\end{abstract}

Dessa exposição percebe-se que em relação a impostos, não há uma "tributação ambiental". Há sim um mecanismo de concessão de benefícios fiscais e isenções tributárias a serem feitas através de lei específica, conforme estipula o art. $150, \S 6^{\circ}$ da CF. Isto não implica qualquer criação de tributo com vistas a onerar a atividade produtiva, mas sim auxiliar àqueles que possuem cadeia produtiva compatível com a preservação ambiental.

Tal mecanismo pode ser feito em qualquer esfera de poder tributante, seja ele federal, estadual e municipal. Atualmente, ocorre de forma expressiva em âmbito estadual, com

\footnotetext{
${ }^{10}$ LUZ, Luis Augusto Stumpf. Tipo Tributário Aberto: uma perspectiva ambientalista In BARICHELO, Stefania Eugenia e ARAÚJO, Luiz Ernani Bonesso. Fórum de Direito Urbano e Ambiental - FDUA. ano 1, n.1, jan/fev. 2002. Belo Horizonte: Fórum, 2002, p.71
} 
relação ao imposto sobre operações relativas à circulação de mercadorias e sobre prestações de serviços de transporte intermunicipal e interestadual e de comunicação - ICMS, previsto no art. 155, II da CF, o qual será analisado posteriormente.

A concessão de benefícios e isenções fiscais no âmbito estadual poderia ser estendido ao imposto de propriedade de veículo automotor - IPVA, já que pode estimular a compra de automóveis movidos a combustíveis menos poluidores, como por exemplo, os de combustão a álcool ou gás natural veicular, frente aos movidos a gasolina ou diesel.

Os impostos aduaneiros, mais precisamente os impostos de importação (II) e exportação (IE), possuem uma forte característica extrafiscal, na medida em que, juntamente com o imposto sobre produtos industrializados (IPI) e os das "operações financeiras" (IOF), tem grande poder interventivo no domínio econômico.

Desse modo, os imposto aduaneiros, assim como os outros dois não estão vinculados aos princípios da legalidade tributária, anterioridade nem à noventena, podendo suas alíquotas serem majoradas por resolução do Ministério da Fazenda, (II e IE) ou por decreto presidencial (IPI e IOF).

No tocante aos imposto aduaneiros, a majoração das alíquotas aos contribuintes que desrespeitam as regras ambientais, podem ensejar uma forte reprimenda a eles, forçando-os a se adequarem de modo vantajoso ao meio ambiente. Ou seja, contribuintes exportadores, que em sua atividade empresarial não toma cuidados para amenizar ou erradicar os impactos ambientais, podem ser onerados em seus produtos, a fim de que repensem e invistam em melhorias internas, com o escopo de preservar o meio ambiente. Por outro lado, contribuintes importadores que adquiram produtos de outrem que comprovadamente prejudica o meio ambiente, também podem ser onerados, induzindo-os a buscar novos parceiros, que respeitem o meio ambiente, ou deixando de utilizar produtos poluidores.

Contribuintes que têm esta preocupação ambiental possuem um custo mais elevado em sua produção, em comparação com aqueles que não se importam com o meio ambiente, gerando um desequilíbrio na livre concorrência, já que este último fornecerá produtos e serviços com preços menores ao consumidor final. Daí a necessidade de intervenção do Estado, para reequilibrar esta concorrência, onerando os poluidores. Caso contrário, aqueles que exercem empresa conforme a função sócio-ambiental seriam penalizados em benefício dos poluidores.

Esta atuação estatal na seara tributária acaba se relacionando com o atendimento do princípio ambiental do poluidor-pagador, presente no art. $4^{\circ}$, VII, da Lei $n^{\circ}$ 6938/81, a qual dispõe sobre a Política Nacional do Meio Ambiente, impondo ao poluidor e ao predador, a 
obrigação de recuperar e/ou indenizar os danos causados, e ao usuário, da contribuição pelo uso dos recursos naturais com fins econômicos. Em outros termos, o contribuinte-poluidor acaba "pagando" mais aos cofres públicos, pela sua atuação nociva ao meio ambiente, forçando-o a investir em sua produção, a fim de ser ecologicamente correta. Isto cria uma consciência ambiental em âmbito nacional e internacional.

Nada mais justo, portanto, do que beneficiar os contribuintes que possuem consciência ambiental, com incentivos e isenções fiscais.

\subsection{Taxas}

Pela redação do art. 145, II, da CF e do art. 77 do CTN, as taxas são uma das espécies tributárias, cujo fato gerador é o exercício regular do poder de polícia ou pela utilização, efetiva ou potencial, de serviços públicos específicos e divisíveis, prestados ao contribuinte, ou postos à sua disposição.

Note que a taxa é um tributo vinculado a uma contraprestação do Estado ao contribuinte, seja ela uma taxa de polícia ou uma taxa de serviço.

O caráter extrafiscal da taxa encontra-se no exercício regular do poder de polícia. Quanto mais poluidora for a atividade produtiva ou quanto maior o gasto na fiscalização, por parte do Estado, a essas atividades, maiores seriam os valores das taxas a serem pagos.

Atividades econômicas que causem grandes impactos ambientais e requeiram constante vigilância estatal, podem ser oneradas por taxas de licenciamento ambiental mais gravosas. Este tributo também pode incidir este tributo sobre os dejetos destas atividades, sejam eles sólidos, líquidos ou gasosos, potenciais poluidores do solo, das águas e do ar.

Contribuintes cuja atividade cause poluição sonora, podem sofrer com majorações taxativas, na medida em que irão dar margem a constantes fiscalizações estatais.

Um exemplo de "taxa ambiental" é a instituída em Pernambuco, presente na Lei $\mathrm{n}^{\mathrm{o}}$ 10.403/89, art. 84, que prevê: “a utilização, efetiva ou potencial, por parte das pessoas visitantes, da infra estrutura física implantada no Distrito Estadual e do acesso e fruição ao patrimônio natural e histórico do Arquipélago de Fernando de Noronha.”

Dessa forma, as taxas tem esse condão extrafiscal, podendo incentivar a preservação ambiental.

\subsection{Contribuições de Melhoria}

Pelo art. 145, III da CF, temos que a contribuição de melhoria decorre de obras públicas. 
O CTN em seu art. 81, expõe uma conceituação mais completa:

\begin{abstract}
A contribuição de melhoria cobrada pela União, pelos Estados, pelo Distrito Federal ou pelos Municípios, no âmbito de suas respectivas atribuições, é instituída para fazer face ao custo de obras públicas de que decorra valorização imobiliária, tendo como limite total a despesa realizada e como limite individual o acréscimo de valor que da obra resultar para cada imóvel beneficiado.
\end{abstract}

Basicamente, a contribuição de melhoria será cobrada dos contribuintes que tiveram acréscimo patrimonial em virtude de uma arborização no bairro, construção de uma praça, construção de um parque ambiental, onde o aspecto ambiental é valorizado, ou até mesmo reflorestamento de áreas degradadas que determinam a valorização. Em outras palavras será uma obra pública "verde", ensejadora do pagamento deste tributo.

Segundo Roberto Ferraz no Congresso Internacional de Direito Ambiental, a contribuição de melhoria:

\begin{abstract}
levaria a uma equação muito diferente, e justa, na criação de parques e áreas de preservação ambiental. O Poder Público ao decidir criar áreas de preservação ambiental, como praças, parques e reservas, particularmente junto a aglomerações urbanas: a) avaliaria a área e suas redondezas, como manda a lei relativa à contribuição de melhoria; b) exigiria a contribuição correspondente à valorização dos imóveis circunvizinhos à área de preservação (obra pública); c) indenizaria o proprietário do imóvel sobre o qual recai a preservação obrigatória, pelo valor real do imóvel, com os recursos advindos dessa arrecadação; d) teria condições de arcar com novas desapropriações semelhantes. Também a utilização da contribuição de melhoria como tributo ambientalmente orientado traz possibilidades infindáveis. Não se trata aqui de induzir comportamentos, mas de viabilizar economicamente, e com justiça fiscal, a efetivação de políticas públicas ambientais. ${ }^{11}$
\end{abstract}

Apesar de seu pouco uso no cotidiano tributário nacional, tal tributo pode contribuir para que haja uma proteção substancial do meio ambiente urbano, favorecendo o convívio hormônio entre homem e natureza.

\title{
4.4 Empréstimos Compulsórios
}

Com base no art. 148 da CF, os empréstimos compulsórios são tributos de competência da União e só poderão ser instituídos por intermédio de lei complementar, para atender a despesas extraordinárias decorrentes de calamidade pública, de guerra externa ou sua iminência; bem como no caso de investimento público de caráter urgente e de relevante interesse nacional.

\footnotetext{
${ }^{11}$ FERRAZ, Roberto; Araújo, João Augusto Aquino de. Tributação Ambiental orientada - possibilidades no Brasil. In: CONGRESSO INTERNACIONAL DE DIREITO AMBIENTAL: FAUNA, POLÍTICAS PÚBLICAS E INSTRUMENTOS LEGAIS, 8., 2004, São Paulo. Anais... São Paulo, 2004. p.663-678. In BARICHELO, Stefania Eugenia e ARAÚJO, Luiz Ernani Bonesso. Fórum de Direito Urbano e Ambiental FDUA. ano 1, n.1, jan/fev. 2002. Belo Horizonte: Fórum, 2002.
} 
Tal tributo possui um caráter emergencial em sua cobrança. É fato que uma calamidade pública relacionada ao meio ambiente, poderá dar margem à possibilidade de cobrança deste tributo, por parte da União.

Todavia, é extremamente difícil que isto ocorra, pois a União lançará mão de outros mecanismos tributários para obter recursos, a fim de atender àquela situação emergencial.

As chuvas catastróficas que atingiram Santa Catarina e Paraná, no fim do ano de 2008 e início deste ano, geraram situação de calamidade pública, na medida em que fenômenos da natureza ocasionaram a enchente de rios e liquefação de morros, gerando enormes prejuízos patrimoniais e ambientais. Mesmo assim, a União não utilizou o artifício do empréstimo compulsório para reconstruir os municípios devastados, bem como recuperar as atividades econômicas da região.

Campanhas de doação de mantimentos foram feitas a nível nacional, com o intuito de auxiliar as dezenas de milhares de famílias desabrigadas, vítimas desta catástrofe ambiental. O povo brasileiro respondeu ao chamamento do Estado, enviando toneladas de roupas e alimentados, dispensando a União de instituir empréstimos compulsórios, o que oneraria ainda mais o contribuinte.

Vale lembrar que o empréstimo compulsório tem arrecadação vinculada às situações elencadas na $\mathrm{CF}$ :

Art. 148, parágrafo único. A aplicação dos recursos provenientes de empréstimo compulsório será vinculada à despesa que fundamentou sua instituição.

O CTN estabelece regra primordial para caracterizar esta espécie tributária:

Art. 15, parágrafo único. A lei fixará obrigatoriamente o prazo de empréstimo e as condições de seu resgate, observando, no que for aplicável, o disposto nesta Lei.

Das linhas deste dispositivo torna-se claro que a lei complementar instituidora do empréstimo compulsório tem que conter, expressamente, o prazo de restituição dos valores arrecadados, como forma de atender, completamente, ao princípio da legalidade tributária, norte de toda atividade tributária.

Caso tal medida não venha a se concretizar, estará caracterizado o caráter confiscatório do tributo, por parte do ente tributante competente, violando o disposto no art. 150, IV da CF, possibilitando a adoção de medidas sancionatórias à União, através da via judicial, bem como possível ressarcimento de danos.

\subsection{Contribuições Especiais}

Previstas no art. 149 da CF: 
Compete exclusivamente à União instituir contribuições sociais, de intervenção no domínio econômico e de interesses das categorias profissionais ou econômicas, como instrumento de sua atuação nas respectivas áreas, observado o disposto nos arts. 146 , III, e 150 , I e III e sem prejuízo do previsto no art. $196, \S 6^{\circ}$, relativamente às contribuições a que alude o dispositivo.

Tais contribuições se diferenciam daquelas elencadas no art. 149-A da Lei Maior, cujo teor dispõe que Municípios e o Distrito Federal poderão instituir contribuição para o custeio de serviço de iluminação pública, com observância ao art. 150, I e III da mesma Lei. Também se contrapõe àquelas que podem ser instituídas por Estados e Municípios, de acordo com o art. $149, \S 1^{\circ}$ da CF.

Decorre do dispositivo em destaque que as contribuições especiais se ramificam em três subtipos. As contribuições sociais, as de intervenção no domínio econômico e as ditas corporativas.

Destes três subtipos apenas um deles possui característica que pode ser utilizada para a extrafiscalidade, antes de mencionarmos isto, devemos elucidar os motivos de tal conclusão.

As contribuições sociais elencadas no art. 149 retrocitado, primeira parte, tem sua arrecadação destinada ao atendimento dos fins do Instituto Nacional da Seguridade SocialINSS. Tal espécie tributária viabiliza parte do custeio da seguridade social brasileira.

Por sua vez, as contribuições de interesse das categorias profissionais ou econômicas têm como finalidade carrear recursos para as entidades de classe, com o intuito de fortalecêlas e dotarem de autonomia financeira, a fim de que prestem seu serviço de defender os profissionais afiliados.

Desta feita, sobra somente a contribuição de intervenção no domínio econômico CIDE com força suficiente para contribuir com a preservação do meio ambiente, na medida em que detém característica de extrafiscalidade.

Pelo art. 170, VI da CF, a defesa do meio ambiente é princípio da ordem econômica, e para ser levado a cabo pelo Estado em colaboração com a iniciativa privada, a União pode disponibilizar dos recursos arrecadados com a cobrança de tais contribuições, com a finalidade de reduzir os impactos ambientais de certos setores produtivos.

Um exemplo disto é a cobrança de CIDE do setor madeireiro para viabilizar atividades de reflorestamento nas áreas degradadas ${ }^{12}$. Também se pode pensar na indústria joalheira pagar contribuição interventiva, com a finalidade de despoluir rios e evitar o uso de mercúrio

\footnotetext{
${ }^{12}$ COSTA, Regina. Tributação Ambiental. In: FREITAS, Vladimir Passos de (Org). Direito ambiental em evolução. p. 306. In: In BARICHELO, Stefania Eugenia e ARAÚJO, Luiz Ernani Bonesso. Fórum de Direito Urbano e Ambiental - FDUA. ano 1, n.1, jan/fev. 2002. Belo Horizonte: Fórum, 2002.
} 
nos garimpos. A indústria mineradora também pode contribuir para a preservação do meio ambiente, na medida em que sua atividade é extremamente impactante aos biomas terrestres.

A margem de manobra nas mãos do Executivo no que se refere à CIDE permite que este tipo tributário direcione parte dos recursos para a preservação ambiental.

\section{A REPARTIÇÃO CONSTITUCIONAL DE RECEITAS TRIBUTÁRIAS E A POLÍTICA NACIONAL DE MEIO AMBIENTE}

A repartição de receitas tributárias prevista na Constituição Federal, presente dos arts. 157 a 162, poderia viabilizar a política nacional de meio ambiente, no tocante à preservação ambiental, todavia, acarretaria grandes incongruências e geraria prejuízos aos entes da Federação brasileira.

Da leitura destes dispositivos, vislumbra-se que:

a) cabe aos Estados e ao Distrito Federal, a totalidade do imposto de renda, incidentes na fonte, sobre rendimentos pagos, a qualquer título por eles, e suas autarquias e fundações que criarem e mantiverem, Ademais, a União entregará 21,5\% (vinte e um vírgula cinco por cento) da arrecadação do imposto de renda (IR) e do imposto sobre produtos industrializados (IPI), separadamente, para o Fundo de Participação dos Estados; bem como 3\% (três por cento) da arrecadação destes tributos a programas de financiamento ao setor produtivo da regiões Norte, Nordeste e Centro-Oeste e ainda, 10\% (dez por cento) da arrecadação do IPI aos Estados e Distrito Federal de forma proporcional ao valor das respectivas exportações de produtos industrializados. Além disso, 30\% (trinta por cento) do imposto sobre "operações financeiras" incidente sobre o ouro - IOF-ouro, de competência da União, é repassado aos Estados e Distrito Federal. Por fim, 29\% (vinte e nove por cento) do produto da arrecadação da CIDE (art. 177, $\$^{\circ}$ da CF), são destinados aos Estados.

b) aos Municípios cabem 22,5\% (vinte e dois vírgula cinco por cento) da arrecadação do IR e do IPI ao Fundo de Participação dos Municípios; 70\% (setenta por cento) da arrecadação do IOF-ouro, é destinado ao município de origem da jazida. Por último, a eles cabem o produto da arrecadação do imposto da União sobre a renda e proventos de qualquer natureza, incidentes na fonte, sobre rendimentos pagos, a qualquer título por eles, suas autarquias e fundações que instituírem e mantiverem; $50 \%$ (cinqüenta por cento) do produto da arrecadação do imposto da União sobre a propriedade rural; $50 \%$ (cinqüenta por cento) do imposto do Estado sobre a 
propriedade de veículos automotores; $25 \%$ (vinte e cinco por cento) da arrecadação do imposto do Estado incidente sobre operações relativas à circulação de mercadorias e sobre prestações de serviços de transporte interestadual e intermunicipal e de comunicação e, $25 \%$ (vinte e cinco por cento) dos $29 \%$ (vinte e nove por cento) da CIDE destinadas aos Estados.

Sendo assim, a União poderá ampliar a repartição desta receitas aos Estados e Municípios que adotassem políticas públicas atinentes à preservação do meio ambiente. Contudo, necessita-se de um cálculo detalhado e trabalhoso para contemplar, de forma individual, Estados e Municípios que privilegiassem em seu território o meio ambiente. É como se houvesse uma fiscalização nos mais de cinco mil municípios e nos vinte e seis estados, além do Distrito Federal, para a visualização de políticas ambientais. Enorme trabalho ao Ministério do Meio Ambiente - MMA, por intermédio do Instituto Brasileiro de Meio Ambiente - IBAMA, assim como às secretarias estaduais e municipais de meio ambiente, as quais carecem, muito mais do que o órgão federal, de recursos humanos e financeiros.

Tal ato leva em consideração a criação de áreas de preservação ambiental estaduais e municipais nos limites destes entes federados em detrimento do setor econômico em geral. Em outras palavras, incentivam-se setores econômicos como o de turismo/hotelaria, farmacêutico/bioquímico, que podem conviver de modo salutar com o meio ambiente.

Porém, o incentivo a tais agentes produtivos nem sempre é garantia de valorização econômica de uma dada localidade, ou seja, é preciso levar em consideração a vocação econômica de cada local, a fim de que nenhum recurso deixe de ser utilizado em prol do meio ambiente. Por exemplo, jazidas minerais jamais vão deixar de ser exploradas economicamente, em benefício da intangibilidade do meio ambiente.

O que se deve ter em mente é o manejo ecológico e racional dos recursos naturais, com o escopo de garantir o equilíbrio ambiental nas diversas regiões do Brasil.

Por outro lado, haverá uma açodada procura pela instituição de áreas de preservação ambiental federais nos territórios estaduais, que poderá abranger diversos municípios, inclusive. Isto levaria a um caos do setor produtivo, pois localidades inteiras seriam intocáveis e inexploradas economicamente, em troca de um maior naco de recursos da repartição de receitas provenientes do orçamento da União.

Portanto, a repartição de receitas tributárias vislumbradas do ângulo União-Estadomembro previstas constitucionalmente, poderá provocar enormes problemas para a economia nacional, gerando desestruturação da cadeia produtiva nacional. 
Todavia, ao analisarmos esta mesma repartição de tributos do ângulo Estado-membroMunicípio, perceberemos que a relação tributária-ambiental é mais palpável e viável do ponto de vista da efetivação, pois além de ter um espaço geográfico reduzido, é onde os benefícios ambientais são sentidos em sua completude, tendo em mente que a maioria da população brasileira vive na zona urbana. É sob este enfoque que se concentram as experiências nacionais em que os tributos contribuem para a proteção ambiental.

\section{EXPERIÊNCIAS NACIONAIS ACERCA DA RELAÇÃO TRIBUTO - MEIO AMBIENTE}

A realidade tributária nacional já conhece experiências bem sucedidas, sendo que a principal delas encontra-se na repartição de receita tributária. É o caso do "ICMS- Ecológico", implementado por vários Estados-membros da federação, isto é, parte deste tributo que é repassado aos municípios é distribuído em maior volume ao município que cria práticas de proteção ambiental.

Contudo, existem também exemplos que fogem da repartição de receitas e se caracterizam pelo fato de que parte da arrecadação de certos tributos são destinados à preservação ambiental, que serão vistos posteriormente.

É forçoso lembrar que sendo assim não há que se falar em “tributação ambiental", pois não existe a instituição de novos tributos com fins de zelo pelo meio ambiente, mas sim uma releitura do caráter extrafiscal de cada tributo e a sua capacidade de colaborar com a proteção do meio ambiente, seja através de isenções e incentivos fiscais, seja através de nova formação da repartição tributária no âmbito dos entes federados.

Desta maneira, o pioneiro desta forma de interrelação entre os dispositivos constitucionais da repartição de receitas tributárias, portanto do desenvolvimento sustentável, e a política nacional de proteção ao meio ambiente foi o Estado do Paraná. Os fundamentos legais decorrem do art. 158, parágrafo único, II da CF, da Constituição do Estado - art. 132, bem como da lei complementar estadual $n^{\circ}$ 59/91 e os decretos estaduais $n^{\circ}$ 974/91 e 2791/ 96. Em síntese, $5 \%$ (cinco por cento) dos 25\% (vinte e cinco por cento) do ICMS destinado aos municípios paranaenses são direcionados àqueles que criaram unidades de conservação e restrições ao uso do solo nas proximidades de mananciais de abastecimento, bem como o estabelecimento de coeficientes mensuráveis de biodiversidade para que o repasse seja efetivado. Ou seja, há um incremento da verba destinada aos municípios que adotam políticas de proteção ao meio ambiente. 
O mesmo percentual de 5\% (cinco por cento) é encontrado no Mato Grosso do Sul, com base no art. 153,II, parágrafo único, I da Constituição Estadual, na lei complementar 77/94, nas leis $\mathrm{n}^{\mathrm{o}} 2.193 / 00$ e 2.259/01 e no decreto estadual 10.478/01, considerando os mesmos critérios do Paraná; no Estado de Pernambuco, com fulcro na Lei $n^{\circ} 11.899 / 00$ e Decreto Estadual 23.473/01, que valoriza os municípios que possuem unidade de conservação e os que tem unidades de compostagem ou aterro sanitário controlado; em Rondônia, de acordo com a lei complementar $n^{\circ}$ 147/96, que privilegia a relação entre a área municipal preservada e a área do Estado; no Acre, com suporte na lei 1.530/04, valorizando todos os tipos de proteção ambiental presente nas leis federais, como por exemplo as estações ecológicas, parques ecológicos etc. e, em Goiás, com base no art. 107, §1 ${ }^{\circ}$ da Constituição Estadual, que prioriza a fiscalização, defesa, preservação e recuperação ambientais e,

No Rio Grande do Sul, o percentual sobe para 7\% (sete por cento) do ICMS gaúcho ao municípios, baseado em critério da relação da área municipal frente a estadual, de acordo com a Lei no 11.038/97. Já no Mato Grosso, o mesmo percentual é dado aos municípios que tem as suas unidades de conservação, bem como a proteção indígena e para aqueles que tem serviço de esgoto sanitário e coleta de lixo adequada, práticas elencadas nas lei complementar 73/00 e nos decretos estaduais $n^{\circ} 2.580 / 01$ e 2.758/01.

No Estado de Tocantins, o percentual destinado cai para 3,5(três e meio por cento), o qual premia os municípios que seguem a política nacional do meio ambiente, criam unidades de conservação, protegem terras indígenas, combate às queimadas e, conservam o solo e a água. Tudo isto com fundamento na lei no 1.323/02.

No Estado do Rio de Janeiro, a distribuição cai ainda mais para 2,5\% (dois e meio por cento), que será feito de forma gradual entre os anos de 2009 e 2011, com base na lei n $^{\text {o }}$ 5.100/07, enaltecendo os municípios que implantam áreas de preservação permanente, cuidam do lixo sólido e preservam os mananciais hídricos que abastecem a população fluminense.

Já os Estados de São Paulo e Minas Gerais destinam apenas 1\% (um por cento) do ICMS repassados aos municípios, àqueles que zelam pelo meio ambiente saudável e duradouro. Os paulistas o fazem sob a égide das leis $n^{\circ} 8.150 / 93,9.146 / 95$ e 10.544/00. Por sua vez, os mineiros estão calcados na lei $n^{\circ}$ 12.040/95.

Deixando o campo das repartições tributárias, entramos no campo em que dispositivos legais asseguram que certos tributos terão destinação para a preservação ambiental ou estabelecem incidência de gravames de atividades que auxiliam na proteção do bioma brasileiro. 
A CF em seu art. 177, §4 , II, “b”, diz que a CIDE relativa às atividades de importação ou comercialização de petróleo e seus derivados, gás natural e seus derivados, assim como álcool combustível terão seus recursos destinados ao financiamento de projetos ambientais. Tal dispositivo foi regulamentado pela Lei $\mathrm{n}^{\circ} 10.636 / 02$ que dispõe:

\begin{abstract}
Art. 4 Os projetos ambientais relacionados com a indústria do petróleo e do gás a serem contemplados com recursos da Cide, conforme estabelece a alínea "b" do inciso II do $\S 4^{\circ}$ do art. 177 da Constituição Federal, serão administrados pelo Ministério do Meio Ambiente e abrangerão: I - o monitoramento, controle e fiscalização de atividades efetiva ou potencialmente poluidoras; II - o desenvolvimento de planos de contingência locais e regionais para situações de emergência; III - o desenvolvimento de estudos de avaliação e diagnóstico e de ações de educação ambiental em áreas ecologicamente sensíveis ou passíveis de impacto ambiental; IV - o apoio ao desenvolvimento de instrumentos de planejamento e proteção de unidades de conservação costeiras, marinhas e de águas interiores; V - o fomento a projetos voltados para a preservação, revitalização e recuperação ambiental em áreas degradadas pelas atividades relacionadas à indústria de petróleo e de seus derivados e do gás e seus derivados; VI - o fomento a projetos voltados à gestão, preservação e recuperação das florestas e dos recursos genéticos em áreas de influência de atividades relacionadas à indústria de petróleo e de seus derivados e do gás e seus derivados. VII - o fomento a projetos voltados à produção de biocombustíveis, com foco na redução dos poluentes relacionados com a indústria de petróleo, gás natural e seus derivados.
\end{abstract}

Acrescenta-se a isto, a lei $\mathrm{n}^{\mathrm{o}} 11.116 / 05$ que prevê benefícios tributários aos produtores e importadores de biodiesel, produto combustível com reduzida capacidade poluidora estimulado pelo governo brasileiro, a exemplo do álcool combustível.

Temos, também, a incidência do Imposto sobre Serviços, de competência dos municípios, nas atividades de reciclagem, conforme os ditames da Lei Complementar $\mathrm{n}^{\circ}$ 116/03, no item 7, sub-item 7.09. Vale ressaltar que a reciclagem é atividade de preservação do meio ambiente, gerando receita para o município que fomenta esse setor econômico.

A taxa, pelos motivos já explicitados anteriormente auxilia no zelo ambiental. Sendo assim a lei $n^{\circ}$ 6.938/81, em seu art. 17-B, acrescentado pela lei $n^{\circ} 10.165 / 02$, prevê a instituição da Taxa de Controle e Fiscalização Ambiental - TCFA, cujo fato gerador é o exercício regular do poder de polícia conferido ao Instituto Brasileiro do Meio Ambiente e dos Recursos Naturais Renováveis - IBAMA para controle e fiscalização das atividades potencialmente poluidoras e utilizadoras de recursos naturais

Por fim, outro exemplo está no Município do Rio de Janeiro, na lei municipal $\mathrm{n}^{\circ}$ 1364/88, que estabelece o pagamento de contribuição de melhoria dos proprietários que tiveram imóveis valorizados por obras públicas como arborização de ruas e praças, construção ou ampliação de parques, proteção contra a erosão, aterros e outras obras de embelezamento, como também, a hipótese de projeto de tratamento paisagístico. 


\section{REFORMA TRIBUTÁRIA BRASILEIRA E OS TRATADOS INTERNACIONAIS - IMPACTOS NA POLÍTICA NACIONAL DO MEIO AMBIENTE}

O processo de globalização das relações comerciais acarretou um incremento no fluxo de pessoas e de capital, ao redor do globo.

Diante deste processo internacional, os Estados se encarregaram de intensificar o intercâmbio comercial ao estreitarem as suas relações por meio de tratados internacionais.

De todo modo, existem dois pontos fundamentais que se complementam em prol de uma benéfica parceria, mas que pela sua complexidade de implementação e pelo fato de sofrerem influências circunstanciais dos interesses em questão são tratadas com elevado cuidado pelos países. Estamos falando da elaboração e celebração de tratados internacionais, bem como da proposta de reforma tributária brasileira.

O processo de elaboração destes tratados internacionais é complexo e demorado, devido aos inúmeros aspectos que envolvem as relações internas e externas de cada Estado. Deste modo, e devido à importância do tema para o entendimento internacional dos Estados, necessitou-se da celebração de uma convenção para tratar, especificamente, de tratados internacionais, no ano de 1969.

A Convenção de Viena sobre os Direitos dos Tratados de 1969 estipula todas as regras para a celebração de tratados internacionais, contudo, só começou a vigorar somente em 27 de janeiro de 1980, quando se atingiu o quorum mínimo de trinta e cinco Estados-partes, em conformidade com o seu art. 84.

No contexto brasileiro esta convenção ainda não se tornou válida, apesar de que o texto desta convenção ter sido enviado ao Legislativo Federal desde o dia 22 de abril de 1992, sem que tenha sido apreciado, para que tenha validade na ordem jurídica nacional. Porém, o Governo Brasileiro através do Ministério das Relações Exteriores tem se pautado nos princípios desta convenção, para a celebração, formação e consolidação de tratados internacionais que o Brasil venha a pactuar com entes estrangeiros.

De acordo como ao art. $2^{\circ}, \S 1^{\circ}$, letra a da Convenção de Viena sobre os Direitos dos Tratados, o termo tratado internacional consiste em um "acordo internacional concluído por escrito entre Estados e regido pelo Direito Internacional, que conste de um instrumento único, quer de dois ou mais instrumentos conexos, qualquer que seja sua denominação específica".

Nas palavras de Valério de Oliveira Mazzuoli o processo de formação dos tratados internacionais possui quatro fases: 
a) a das negociações preliminares; b) a da assinatura ou adoção pelo Executivo; c) a da aprovação parlamentar (referendum) por parte de cada Estado interessado em se tornar parte do tratado; e por fim, d) a da ratificação ou adesão do texto convencional, concluída com a troca dos instrumentos que a consubstanciam. ${ }^{13}$

Após a fase de ratificação, o tratado ainda necessita de ser promulgado, através de um ato administrativo, no caso o decreto expedido pelo Presidente da República e, finalmente, deve ser publicado no Diário Oficial da União.

Desse modo, a temática dos tratados internacionais possui uma ligação importante com a proposta de reforma do sistema tributário brasileiro, visto que existe há algum tempo, uma problemática acerca da possibilidade ou não de tratados internacionais possuírem normas que permitam isenções tributárias estaduais, na medida em que é necessária a sua incorporação no ordenamento jurídico pátrio, adquirindo um dado status. Tal problemática possui correntes opostas encabeçadas por autores de renome no meio acadêmico tributário.

Pela redação da Emenda Constitucional $n^{\circ}$ 45, de 8 de dezembro de 2004, que acrescentou o parágrafo $3^{\circ}$ do art. $5^{\circ}$ da $\mathrm{CF}$, podemos visualizar três situações distintas sobre o status dos tratados internacionais quando da sua incorporação ao conjunto de leis brasileiras.

A primeira delas trata do fato de que caso os tratados internacionais que versem sobre direitos humanos forem incorporados ao direito pátrio, com os mesmos requisitos necessários para a emendas constitucionais, aqueles terão o mesmo status desta. A segunda trata de que caso os tratados internacionais ou convenções internacionais, mesmo que versem sobre direitos humanos, mas que não tenham sido incorporados pelo procedimento de emendas constitucionais, terão status de lei ordinária. A terceira se refere ao fato de que tratados ou convenções internacionais que versem sobre outra matéria será incorporado como lei ordinária.

Ao lado disso, temos que diante da atual conjuntura de economias dos diversos países interligadas pelo processo de globalização, os tratados internacionais em matéria tributária, normalmente, se atêm ao afastamento da ocorrência de pluritributação, nos casos de impostos diretos, como exemplo típico, os que incidem sobre a renda, bem como ao processo de equalização ou harmonização dos preços das mercadorias, visto o impacto que os impostos indiretos tem sobre tais bens comercializáveis, como exemplo brasileiro, o ICMS ou o IPI. Desse entendimento, os tratados internacionais que versem sobre matéria tributária incorporados ao direito brasileiro, terão a mesma força de lei ordinária nacional e não

\footnotetext{
${ }^{13}$ MAZZUOLI, Valerio de Oliveira. Direito Internacional Público: parte geral. $4^{\text {a }}$ ed. rev., atual. e ampl., São Paulo: Editora Revista dos Tribunais, 2008, p. 53.
} 
puramente federal, pois a União ao celebrar tratados internacionais age com poderes soberanos.

Esclarecendo melhor esta questão, é sabido que a União possui uma dupla face, uma delas encontra-se no fato de que é pessoa jurídica de direito público interno, devendo manter suas ações limitadas à não invasão das competências de Estados, Municípios e Distrito Federal. A outra está vinculada ao fato de ser, ao mesmo tempo, pessoa jurídica de direito público externo, quando atua em nome do estado soberano brasileiro ao estabelecer relações jurídicas com outros estados estrangeiros ou outras organizações internacionais. Nesta dupla atuação se encontra a questão dos tratados internacionais que tratem sobre matéria tributária, pois a União agindo como pessoa jurídica de direito público interno, é vedada a instituição de tributos de competência dos Estados, Municípios e do Distrito Federal, conforme o art. 151, III da CF.

Contudo, quando atua como pessoa jurídica de direito público externo, celebrando tratados ou convenções internacionais, o faz investido de soberania, representando a totalidade do estado brasileiro, portanto, alguns vislumbram a possibilidade desta concessão de isenções fiscais.

Oswaldo Othon de Pontes Saraiva Filho indica que autores importantes da doutrina tributária nacional como Sacha Calmon Navarro Coelho, Valdir de Oliveira Rocha, Hugo de Brito Machado, Luciano Amaro, Denise Lucena Rodrigues, Natanael Martins, Francisco de Paula Souza Brasil, Wagner Balera, Moisés Akselrad, Kiyoshi Harada, Welber Bernal e Antônio Moura Borges, além dele mesmo, são favoráveis a possibilidade de que tratados internacionais sobre matéria tributária possam trazer isenções tributária na seara estadual, municipal e distrital. ${ }^{14}$

Para ele, quando a União estabelece relações com outros estados nacionais ou outras organizações internacionais, ela o está fazendo em nome da República Federativa do Brasil, ente soberano e regularmente reconhecido pela comunidade internacional, com base no art. 21, I a IV da CF. Sendo assim, a isenção tributária perpetrada por normas de tratados ou convenções internacionais celebrados pela União, não invadiriam as competências dos Estados, Municípios ou do Distrito Federal, na medida em que a atuação é feita como Estado Federal, logo os interesses da nação são maiores que os dos entes federados. A vedação seria única e exclusivamente destinada quando a União agisse como pessoa jurídica de direito

\footnotetext{
${ }^{14}$ SARAIVA FILHO, Oswaldo Othon de Pontes. Tratado Internacional pode isentar tributos estaduais, distritais e municipais? In: MOREIRA JUNIOR, Gilberto de Castro e PEIXOTO, Marcelo Magalhães. Org. Direito Tributário Internacional. São Paulo: MP Editora. 2006. p. 280.
} 
público interno. Vale ressaltar que cabe ao Congresso Nacional decidir sobre celebrações internacionais que acarretem encargos ou compromissos gravosos ao país, conforme o art. 49, I da CF.

$\mathrm{Na}$ outra extremidade da questão temos Moreira Alves, Geraldo Ataliba, Misabel Derzi, Alcides Jorge Costa, Ives Gandra da Silva Martins e outros ${ }^{15}$ os quais são contrários ao entendimento acima exposto.

Eles tem em comum o argumento de que o Brasil não adotou a teoria monista do direito internacional, a qual prega a cláusula geral de recepção plena e eficaz dos tratados internacionais, onde eles automaticamente valem na ordem interna. $\mathrm{O}$ tratado ou convenção internacional precisa passar por um processo de aceitação na ordem interna, estabelecido na própria CF. Desse modo, o processo de aceitação dará o status que tal acordo, ou seja, será equiparado a alguma das formas do art. 59, I a III da CF.

Por sua vez, o CTN estipula nos arts. 96, 98 e 100 que os tratados internacionais ou convenções internacionais fazem parte da legislação tributária. Contudo, se sabe que o nível com que tais celebrações internacionais são recepcionadas na ordem interna consiste em lei ordinária federal e o próprio CTN foi recepcionado pela CF com lei complementar, portanto há uma diferenciação da natureza jurídica das normas existente. Ademais, mesmo que seja incorporado com lei ordinária nacional, este não tem o poder de afastar leis tributárias estaduais, municipais e distritais, tendo em vista a inexistência de hierarquia entre elas e, sendo como tal, devem respeitar, sobejamente, as competências privativas dos outros entes federados . Tanto uma como outra situação são extremamente conflituosas na ordem jurídica brasileira.

Acrescenta a isto, a regra do art. $150, \S 6^{\circ}$ da $\mathrm{CF}$, que prevê que todo e qualquer subsídio ou isenção, redução de base de cálculo, concessão de crédito presumido, anistia ou remissões de tributos, sejam eles impostos, taxas ou contribuições de melhoria serão feitas por leis específicas a cabo de cada unidade da federação, que regularão, exclusivamente, tais matérias, portanto, não uma sobreposição de competências; e a regra do art. 155, XII, g da CF prevendo que lei complementar estadual ou distrital tratará de isenções, benefícios ou incentivos fiscais.

Roque Antônio Carraza ${ }^{16}$ tem posição intermediária a isto indicando que a União não pode forçar as outras unidades da federação, por intermédio de tratados internacionais, a observarem isenções de tributos locais, mesmo que assumindo outras formas fiscais.

\footnotetext{
${ }^{15} I d$. p. 286.
} 
Em 26 de fevereiro de 2008 foi encaminhada ao Legislativo Federal a proposta de emenda constitucional que trata do Sistema Tributário Nacional, comumente conhecida como reforma tributária. Tem como objetivos simplificar o sistema tributário nacional, avançar no processo de desoneração tributária e eliminar distorções que prejudicam o crescimento da economia brasileira e a competitividade de nossas empresas, principalmente no que diz respeito à chamada "guerra fiscal" entre os Estados.

Uma das propostas é de alteração do art. 151, parágrafo único da Constituição Federal, que ficaria com a seguinte redação: "a vedação do inciso III não se aplica aos tratados internacionais aprovados na forma do art. 49, I." Com tal dispositivo ficaria solucionado a problemática, pois o Congresso Nacional daria a última palavra acerca dos tratados, acordos e atos internacionais. Este ato congressual daria o status devido aos tratados ou convenções internacionais para que interferissem nas legislações tributárias dos Estados, Municípios e Distrito Federal, corroborando entendimento já sedimentado pela jurisprudência do Supremo Tribunal Federal.

É claro que tal regra estaria sujeita a controle de constitucionalidade, mas independente disso, poria termo final à problemática de que isenções e benefícios fiscais de Estados, Municípios e/ou do Distrito Federal poderiam ser dados por acordos internacionais.

Isso geraria um benefício à política nacional do meio ambiente já que por meio de tratativas internacionais, em que o Brasil seja uma das partes interessada, obviamente, incentivos à atividades que valorizem a preservação ambiental possam ser concedidos. Em outros termos, o meio ambiente como objeto de estudo diz respeito a toda humanidade, superando, inclusive a soberania dos Estados, entre eles o Brasil, e as competências privativas de seus entes federados. Seria um enorme e pioneiro passo que o Brasil daria aos demais países, ao servir de paradigma.

É importante frisar que seria mais adequado que estes acordos internacionais fossem feitos por iniciativa e fiscalização da Organização das Nações Unidas (ONU), ou pela Organização Mundial do Comércio (OMC), que, por sua vez, seguiria os preceitos da Convenção de Viena sobre Direito dos Tratados. Isto daria respaldo de legalidade e legitimidade para que a soberania nacional seja relativizada em prol do bem estar da humanidade.

Sendo desta maneira, a proposta de emenda constitucional pode inaugurar uma nova forma do Brasil e dos outros países perceberem que uma atitude mundial no âmbito tributário

\footnotetext{
${ }^{16}$ CARRAZA, Roque Antônio. Mercosul e tributos estaduais, municipais e distritais. Revista de Direito Tributário, n. 64, Malheiros, p. 187.
} 
deles, pode assegurar maior proteção ao meio ambiente, além de promover a harmonização de normas tributária e incrementar o comércio internacional.

\section{ZONEAMENTO ECOLÓGICO-ECONÔMICO - ZEE, SUPERINTENDÊNCIA DA}

\section{ZONA FRANCA DE MANAUS - SUFRAMA E O SISTEMA TRIBUTÁRIO NACIONAL}

A difícil relação existente entre crescimento econômico e o meio ambiente suscitou, há cerca de 20 anos, o surgimento da política governamental de ordenamento territorial brasileiro, que consiste na eficaz conservação do meio ambiente e numa melhor gestão dos recursos naturais.

Possui como base normativa a lei $\mathrm{n}^{\circ}$ 6938/81 que em seu art. $9^{\circ}$, II prevê como instrumento da política nacional do meio ambiente, o zoneamento ambiental.

Apesar de previsão legal há pelo menos 28 anos, somente com o Decreto nº 4297/2002 houve a regulamentação do zoneamento ambiental, que prevê como objetivo, exposto no art. $3^{\circ}:$

\footnotetext{
organizar, de forma vinculada, as decisões dos agentes públicos e privados quanto a planos, programas, projetos e atividades que, direta ou indiretamente, utilizem recursos naturais, assegurando a plena manutenção do capital e dos serviços ambientais dos ecossistemas.
}

O ZEE é uma ferramenta que busca analisar minuciosamente as potencialidades de cada área delimitada, consistente em um ecossistema único, promovendo um desenvolvimento sustentável. Proporciona, portanto, que cada área tenha seus recursos naturais mapeados e como a atividade humana pode utilizá-los de forma harmoniosa. Também tem o viés de analisar os impactos ambientais de certas atividades humanas, como a construção de barragens, por exemplo, na própria região onde está sendo efetivada tal atividade.

O projeto de ZEE verifica os aspectos sociais, levando em consideração a população habitante de cada área, seus costumes e formas de interação com o meio ambiente, proporcionando que haja uma maior integração destas comunidades, na maioria das vezes sediadas em regiões de difícil acesso, seja através de incentivo à formação de cooperativas, seja viabilizando o acesso a informações de manejo sustentável dos recursos naturais, bem como aspectos econômicos, pois estuda as potencialidades econômicas e a possibilidade de existência de atividades produtivas, praticadas pela população local, como a agropecuária, pesca, extrativismo vegetal ou artesanato. Desse modo, as comunidades habitantes destas localidades tem a chance de aumentarem suas rendas, na medida em que possuem uma 
ocupação laboral, fomentando a permanência destas em seus lugares, dificultando a migração destas populações para a periferia das grandes cidades.

O ZEE é feito a nível federal, estadual e municipal, ou seja, há uma capilaridade das iniciativas de mapeamento das áreas e um auxílio integrados às comunidades destas regiões. O fomento ao associativismo proporciona uma melhora na qualidade de vida destas comunidades, através de concessão de benefícios financeiros e fiscais, auxílio de profissionais capacitados que prestam orientação técnica acerca dos produtos naturais a serem explorados, aumentando a produtividade e, interligação com os centros consumidores de tais produtos. A parceria que o ZEE promove entre as instituições governamentais, comunidades produtoras e os setores industrial e de serviços é fundamental para o fortalecimento e diversificação da economia nacional.

Atualmente, com o auxílio do Ministério do Meio Ambiente, existem diversas iniciativas sendo implementadas em todo o território nacional, como por exemplo: o MacroZEE da Amazônia Legal, Base Cartográfica da Amazônia Legal, ZEE da Rodovia BR163, ZEE RIDE-DF, MacroZEE do Nordeste, ZEE da Faixa de Fronteira, ZEE da Bacia Hidrográfica do São Francisco, ZEE da Bacia Hidrográfica do Parnaíba, Rede Virtual da Caatinga, ZEE da Bacia Hidrográfica do Tocantins-Araguaia, ZEE Estaduais e ZEE Municipais.

Percebe-se então que o ZEE se assemelha, guardada as devidas proporções, ao bem sucedido projeto da Zona Franca de Manaus (ZFM), levado a efeito em 28 de fevereiro de 1967. O projeto da ZFM está sob a coordenação da Superintendência da Zona Franca de Manaus - SUFRAMA, autarquia federal, vinculada ao Ministério da do Desenvolvimento, Indústria e Comércio Exterior, que promove o desenvolvimento regional de forma sustentável.

O projeto da ZFM se sustenta sob três pilares, a indústria, o comércio e a agropecuária. Sendo assim, houve uma análise das potencialidades do local nestas três áreas do setor produtivo e fomentou-se estas atividades através de benefícios fiscais.

Através da ZFM, toda a Amazônia Ocidental brasileira foi inserida na economia nacional, de Tabatinga no Estado do Amazonas, fronteira com Letícia-Colômbia à Santana no Estado do Amapá, e de Bonfim no Estado de Roraima à Cacoal no Estado de Rondônia, área da abrangência da ZFM e da SUFRAMA, várias comunidades e sociedades empresárias foram beneficiadas pelos incentivos da ZFM. Ela impulsionou a economia local de tal forma, que atualmente, há um pólo de desenvolvimento de alta tecnologia em Manaus, bem como 
projetos pioneiros de ecoturismo foram desenvolvidos nos mais distantes rincões da Amazônia.

A SUFRAMA tem como missão promover o desenvolvimento sustentável, mediante a geração, atração e consolidação de investimentos, apoiado em capacitação tecnológica, visando a inserção internacional competitiva.

Estabelecendo áreas de desenvolvimento econômico sustentável através dos ZEE's, pode-se estabelecer instituições coordenadoras que irão gerir e distribuir os recursos financeiros, incentivando o desenvolvimento regional. Tais instituições a exemplo da SUFRAMA poderão ser autarquias federais, ligadas a Ministérios que terão basicamente a mesma missão daquela, bem como podem visar as mesmas áreas estratégicas: tecnologia e inovação, atração de investimentos, inserção internacional, desenvolvimento sustentável, logística e desenvolvimento institucional. É fato que zoneamentos estaduais e municipais estão sendo feitos em concomitância com o federal, logo, autarquias estaduais e municipais podem ser criadas com o mesmo objetivo de fiscalizar a atividade produtiva e regular os incentivos fiscais concedidos.

Levando o exemplo da ZFM para o ZEE, percebe-se claramente o auxílio mútuo que o sistema tributário nacional e a política nacional do meio ambiente têm trazido benefícios para o Brasil, ou seja, com incentivos fiscais e uma boa gestão, levou-se desenvolvimento econômico à uma das regiões mais inóspitas do planeta. Assim, a ZFM foi o primeiro zoneamento ecológico-econômico a ser feito no Brasil.

Os contribuintes que se instalarem nestas regiões mapeadas pelo ZEE contribuirão para a preservação ambiental, através de projetos ambientais ou em sua própria atividade produtiva, os quais devem ter benefícios tributários, com o intuito de investirem parte de seus recursos no desenvolvimento sustentável da região. A tributação governamental cederia espaço às práticas protetivas do meio ambiente, gerando empregos e renda para os habitantes destas localidades.

Mais uma vez fica claro que não há uma "tributação ambiental", com instituições de novas exações, mas sim um estímulo àqueles que produzem em harmonia com o meio ambiente.

De fato o que há é uma política tributário-ambiental.

\section{CONCLUSÃO}

O sistema tributário nacional e a política nacional do meio ambiente são instrumentos parceiros na implantação definitiva de um sistema produtivo pautado na proteção ambiental 
ou, se possível, minimizar os impactos ambientais nocivos da atividade humana. O ZEE tem o poder de congregar estas duas forças desenvolvimentistas.

Experiências bem sucedidas como a Zona Franca de Manaus, coordenada pela SUFRAMA, devem ser repetidas nas áreas onde estão sendo feitos os zoneamentos ecológicoeconômicos. São futuras áreas que guardarão as novas fronteiras da economia nacional, seja ela industrial, comercial, agropecuária ou do ecoturismo. Ademais, é primordial a atuação do Estado Brasileiro, seja a nível federal, estadual e municipal, através da criação de instituições gestoras destas áreas, com o intuito de viabilizar o eficaz manejo sustentável dos recursos naturais, assegurando benefícios não só para àqueles que exploram os recursos naturais, mas também para toda a nação brasileira, uma vez que o meio ambiente é bem constitucional de uso comum de todos.

Como os tributos são uma invasão permitida por lei ao patrimônio particular e tem a finalidade de sustentar as atividades estatais, nas áreas mapeadas pelo zoneamento ecológicoeconômico terão sua função extrafiscal exarcebada em prol de um desenvolvimento econômico apropriado, na medida em que fomentam práticas e iniciativas que visam a preservação dos ecossistemas nacionais, bem como valorizam a utilização mão-de-obra local inserindo grande contingente populacional na economia formal, promovem o avanço tecnológico e viabilizam o surgimento de uma logística de escoamento da produção.

Desse modo, o ZEE engloba aspectos tributários e ambientais garantindo o desenvolvimento nacional e diminui as desigualdades regionais, objetivos fundamentais do Estado Brasileiro, estampado no art. $4^{\circ}$ da $\mathrm{CF}$, através do mapeamento das potencialidades econômicas das regiões, assim como possibilitando a implantação de projetos economicamente e ambientalmente sustentáveis. Em outros termos o ZEE é o instrumento de uma política tributário-ambiental, levado a efeito pelo Estado Brasileiro.

Por fim, é equivocado analisar a extrafiscalidade dos tributos em relação ao meio ambiente como uma "tributação ambiental", mas podemos denominar tal iniciativa doutrinária de "extrafiscalidade pró-ambiente" ou de "extrafiscalidade verde".

\section{REFERÊNCIAS BIBLIOGRÁFICAS}

ALEXANDRE, Ricardo. Direito tributário esquematizado. $2^{\mathrm{a}}$ ed. atual. ampl. São Paulo: Método, 2008.

AMARO, Luciano. Direito Tributário Brasileiro. $13^{\mathrm{a}}$ ed. rev.atual. São Paulo: Saraiva, 2007. 
CARRAZA, Roque Antônio. Mercosul e tributos estaduais, municipais e distritais. Revista de Direito Tributário, n. 64, Malheiros.

COSTA, Regina. Tributação Ambiental. in: FREITAS, Vladimir Passos de (Org). Direito ambiental em evolução. p. 306. in: BARICHELO, Stefania Eugenia e ARAÚJO, Luiz Ernani Bonesso. Fórum de Direito Urbano e Ambiental - FDUA. ano 1, n.1, jan/fev. 2002. Belo Horizonte: Fórum, 2002.

DOMINGUES, José Marcos. Direito Tributário e Meio Ambiente. $3^{\text {a }}$ ed. rev. ampl. Rio de Janeiro: Forense, 2007.

FERRAZ, Roberto; ARAÚJO, João Augusto Aquino de. Tributação Ambiental orientada possibilidades no Brasil. in: CONGRESSO INTERNACIONAL DE DIREITO AMBIENTAL: FAUNA, POLÍTICAS PÚBLICAS E INSTRUMENTOS LEGAIS, 8., 2004, São Paulo. Anais... São Paulo, 2004. p.663-678. in BARICHELO, Stefania Eugenia e ARAÚJO, Luiz Ernani Bonesso. Fórum de Direito Urbano e Ambiental - FDUA. ano 1, n.1, jan/fev. 2002. Belo Horizonte: Fórum, 2002.

FILHO, Oswaldo Othon de Pontes Saraiva. Tratado Internacional pode isentar tributos estaduais, distritais e municipais? in: JUNIOR, Gilberto de Castro Moreira e PEIXOTO, Marcelo Magalhães. Org. Direito Tributário Internacional. São Paulo: MP Editora. 2006.

LUZ, Luis Augusto Stumpf. Tipo Tributário Aberto: uma perspectiva ambientalista. in BARICHELO, Stefania Eugenia e ARAÚJO, Luiz Ernani Bonesso. Fórum de Direito Urbano e Ambiental - FDUA. ano 1, n.1, jan/fev. 2002. Belo Horizonte: Fórum, 2002.

MAZZUOLI, Valério de Oliveira. Direito Internacional Público: parte geral. $4^{\mathrm{a}}$ ed. rev., atual. e ampl., São Paulo: Editora Revista dos Tribunais, 2008.

MODÉ, Fernando Magalhães. Tributação Ambiental. Curitiba: Juruá, 2003, p. 123. in BARICHELO, Stefania Eugenia e ARAÚJO, Luiz Ernani Bonesso. Fórum de Direito Urbano e Ambiental - FDUA. ano 1, n.1, jan/fev. 2002. Belo Horizonte: Fórum, 2002.

NUNES, Cleucio Santos. Direito Tributário e Meio Ambiente. São Paulo: Dialética, 2005.

REALE, Miguel. Teoria Tridimensional do Direito. $5^{\text {a }}$ ed. São Paulo: Saraiva, 1994. 
SILVA, José Afonso da. Aplicabilidade das normas constitucionais. $3^{\text {a }}$ ed. rev. e ampl., São Paulo: Malheiros, 1998

SOARES, Guido Fernando Silva. Direito Internacional do Meio Ambiente - Emergência, Obrigações e Responsabilidades. São Paulo: Atlas, 2001.

SOUZA, Jorge Henrique de Oliveira. Tributação e Meio Ambiente. Belo Horizonte: Del Rey, 2009.

TRENNENPOHL, Terence Dornelles. Incentivos fiscais no direito ambiental. São Paulo: Saraiva, 2008. 